\title{
Combination of Spirituality and Cognitive-Behavioral Family Therapy on Treatment of Generalized Anxiety Disorders
}

\author{
Mohammad Khodayarifard ${ }^{1}$, Sayyed Mohsen Fatemi ${ }^{2 *}$ \\ ${ }^{1}$ Faculty of Psychology and Education, University of Tehran, Tehran, Iran \\ ${ }^{2}$ Department of Psychology, Harvard University, Cambridge, USA \\ Email: khodayar@ut.ac.ir, smfatemi@wjh.harvard.edu, "smfatemi@hotmail.com
}

Received June $2^{\text {nd }}, 2012$; revised February $6^{\text {th }}$, 2013; accepted March $7^{\text {th }}, 2013$

Copyright $\odot 2013$ Mohammad Khodayarifard, Sayyed Mohsen Fatemi. This is an open access article distributed under the Creative Commons Attribution License, which permits unrestricted use, distribution, and reproduction in any medium, provided the original work is properly cited.

\begin{abstract}
Therapeutic interventions based on specific religious and spiritual teachings have proven to be effective in dealing with psychological disorders especially general anxiety disorders. Notwithstanding the signs of effectiveness within the integral approaches consisting of religious, spiritual and family therapy's interventions, there are few studies that indicate the exploration of the integrative implications of the aforementioned interventions. Objective: The present research was to examine the effectiveness of integrative therapeutic interventions consisting of spirituality and Cognitive Behavioral Family Therapy on treatment of generalized anxiety disorders. Method: Case study. Participants: Two clients (one male aged 43 and one female, 37 years old). Procedure: Data was obtained based on the clinical interview, DSM-IV-TR criteria, psychological tests and psychiatrist's diagnosis. In the course of 55 weekly therapeutic sessions for the male client and 39 weekly sessions for the female client, a series of techniques with a focus on cognitive restructuring were applied. The participants were also given coaching skills, relaxation skills, problem solving techniques, relationship management skills, and positive psychology techniques. The techniques were: a focus on the integrative implications of spiritual therapy and its emphasis on shared love for all human beings, love for others regardless of their ethnicity, belief in monotheism and belief in the day of judgment and hereafter. Findings: The results of pre-tests and post-tests along with a one year follow-up indicated the efficiency of the treatment while highlighting the vital role of integrative interventions based on spirituality and family cognitive behaviour therapy. The results also supported the role of families in contributing to the treatment of the anxiety disorder. Discussion for Further Research: The enhancement of family members social competencies based on a focus on spirituality and cognitive behavior techniques may facilitate the process of modification of thinking patterns of clients.
\end{abstract}

Keywords: Spirituality; Anxiety Disorders; Family Therapy; Cognitive-Behavioral Approach

\section{Introduction}

There are research findings that confirm the application and implications of both spiritual and religious therapy for treating the general anxiety disorders.

In a case study involving an 18-year-old boy, Walters \& Whitehead (1999) indicated the treatment of anxiety disorder by spiritual therapy. Researchers on psychological issues have applied numerous methods based on their school of thoughts, their research paradigms and their epistemological perspective.

A behaviourist, for example, would classify anxiety as an unwanted conditioned response, perhaps paired with originally neutral stimulus. The social situations that may induce the anxiety can, therefore, be proscribed. The situations can be linked to the inducing responses and therefore an avoidance response may be examined in the context of the situational analysis. Treatment from this perspective then would focus on de-linking this specific response from the stimulus. Likewise, a psychoanalyst would view generalized anxiety as a symptom of a deeper conflict, for instance, low self-esteem. The treatment

\footnotetext{
*Corresponding author.
}

then would focus on improving the client's view of herself (Albucher, 2005).

\section{Diagnostic Criteria for Generalized Anxiety Disorder}

According to Diagnostic and Statistical Manual of Mental Disorders, Fourth Edition Text Revision (DSM-IV-TR, 2000) generalized anxiety disorder is characterized by:

1) Excessive anxiety and worry (apprehensive expectation), occurring more days than not for at least 6 months, about a number of events or activities (such as work or school performance).

2) The person finds it difficult to control the worry.

3) The anxiety and worry are associated with three (or more) of the following six symptoms (with at least some symptoms present for more days than not for the past 6 months).

Note: Only one item is required in children.

a) Restlessness or feeling keyed up or on edge.

b) Being easily fatigued.

c) Difficulty concentrating or mind going blank.

d) Irritability. 
e) Muscle tension.

f) Sleep disturbance (difficulty falling or staying asleep, or restless unsatisfying sleep).

4) The focus of the anxiety and worry is not confined to features of an Axis I disorder, e.g., the anxiety or worry is not about having a Panic Attack (as in Panic Disorder), "being embarrassed in public (as in Social Phobia), being contaminated (as in Obsessive-Compulsive Disorder), being away from home or close relatives (as in Separation Anxiety Disorder), gaining weight (as in Anorexia Nervosa), having multiple physical complaints (as in Somatization Disorder), or having a serious illness (as in Hypochondriasis), and the anxiety and worry do not occur exclusively during Posttraumatic Stress Disorder.

5) The anxiety, worry, or physical symptoms cause clinically significant distress or impairment in social, occupational, or other important areas of functioning.

6) The disturbance is not due to the direct physiological effects of a substance (e.g., a drug abuse, a medication) or a general medical! Condition (e.g., hyperthyroidism) and does not occur exclusively during a Mood Disorder, a Psychotic Disorder, or a Pervasive Developmental Disorder.

The intensity, duration, or frequency of the anxiety and worry is far out of proportion to the actual likelihood or impact of the feared event. The person finds it difficult to keep worrisome thoughts from interfering with attention to tasks at hand and has difficulty stopping the worry. Adults with Generalized Anxiety Disorder often worry about every day, routine life circumstances such as possible job responsibilities, finances, the health of family members, misfortune to their children, or minor matters (such as household chores, car repairs, or being late for appointments). Children with Generalized Anxiety Disorder tend to worry excessively about their competence or the quality of their performance. During the course of the disorder, the focus of worry may shift from one concern to another.

There is considerable cultural variation in the expression of anxiety (e.g., in some cultures, anxiety is expressed predominantly through somatic symptoms, in others through cognitive symptoms). It is important to consider the cultural context when evaluating whether worries about certain situations are excessive.

In children and adolescents with Generalized Anxiety Disorder, the anxieties and worries often concern the quality of their performance or competence at school or in sporting events, even when their performance is not being evaluated by others. There may be excessive concerns about punctuality. They may also worry about catastrophic events such as earthquakes or nuclear war. Children with the disorder may be overly conforming, perfectionist, and unsure of themselves and tend to redo tasks because of excessive dissatisfaction with less than perfect performance. They are typically Overzealous in seeking approval and require excessive reassurance about their performance and their other worries (American Psychiatric Association, 2000).

\section{Cognitive-Behavioral Family Therapy}

In cognitive-behavioral therapies, various strategies are used to alter attitudes and perceptions among clients diagnosed with anxiety. All the theories are based on the assumption that correcting non-adaptive cognition leads to modification of anxiety-avoidance behaviors. Some researchers believe that training the clients in positive self-talk, modelling, mental review, problem solving, self-monitoring and social reinforcements reduce anxiety. The method is especially effective in treatment of anxiety (Kanfer, Karoly, \& Newman, 1975).

Cognitive-behavioral therapy includes several methods the common features of which emphasize the impact of cognitivebehavioral processes in shaping and continuing psychological disorders. In this therapeutic approach, empirical methods based on behaviorism and cognitive therapy are employed to control and treat improper responsive patterns. In addition, in cognitive-behavioral therapy the emphasis is on intervention, via reducing the frequency and intensity of maladaptive responses of the patients to teach new cognitive-behavioral skills to bring about a significant reduction in undesirable conducts and an increase in more adaptive behaviors (Zarb, 1992).

Yongsma and Dattilio (2000) distinguished the following long-term objectives for a cognitive behavioral family therapy and their techniques were used in this research:

1) Employment of cognitive and behavioral methods to reduce anxiety;

2) Gradual confrontation of anxiety creating stimuli;

3) Elimination of intrapersonal, or emotional problems which have contributed to the appearance of the symptoms of anxiety;

4) Informing and educating the family members about the symptoms, roots and treatment of anxiety;

5) Preparing the family members to help each other in reducing anxiety;

6) Informing and educating the family members about employment of specific techniques to reduce anxiety and avoidance behaviors of the person who suffer from anxiety.

In family therapy, many cognitive and behavioral strategies employed.

\section{Spiritual and Ethical Therapy}

Byramkarasu (1999) believes spiritual and ethical therapy is a style of psychotherapy which necessitates taking apart the two concepts of "soul" and "spirit" to get into transpersonal (beyond individual) concepts.

Soul moves in the direction of uncovering the secrets of intimacy and belonging in our daily life, but spirit seeks to find divinity in our secular activities. On this basis, spiritual therapy has been presented based on two important principles: Human being's arriving at soulfulness, which requires him/her to love others, love working and love all of his belongings; and human being's arriving at spirituality, which requires him/her to believe in religion, to have faith in the unity of God and belief in Transformation. Byramkarasu (1999) says that the requirements for spiritual therapy are:

\section{Love towards Others}

This necessitates one to distinguish him/her from other people. In this way the lover and the loved are taken apart, and the individual goes to devotion and self-sacrifice. Then he/she goes to forgiveness. Forgiving releases one from anger, hate, humiliation, and shamefulness. It presupposes that human beings can think of others perfect or flawless.

\section{Love of Working}

When a person loves his job, his work or whatever activity he has, he would do it devotedly and when doing so, he would 
be directed toward his liveliness and happiness. According to this, God is present not only in one's worshiping but also in every part of one's daily activities. So an individual who has faith in God, can progress higher and higher to reach the highest position of exaltedness.

\section{A Sense of Belonging}

Belonging to the society is to cooperate with others and participate in people's activities. This is the cause of good-will, sincerity and spirituality. This requires an individual to free himself/herself from selfishness, self-interest and egotism.

\section{Belief in Holiness and Spirituality}

To believe in spirituality means to respect the sanctity of everything around us. In this way, ordinary objects are experienced as unusual beings. We need to reject all material things of life to reach spirituality. Choosing to live in private is to coordinate the body and soul which eventually leads to belong to Exaltedness.

\section{Belief in the Unity}

The belief in divinity means to feel that one is not distinctive from the outside world (natural and supernatural are together). This brings human being's peace and quiet of life. Belief in unity is the belief of responsibility towards everyone, to feel a multilateral commitment and to feel an equal policy to establish friendly relations with the world around us and get mutually impressed by the integrity of soul, body and mind, which all produce kindness, compassion and purity.

\section{Belief in Resurrection and Life after Death}

This belief highlights the spiritual revitalization and the establishment of a spiritual bond and union. Death, in this way, would be the preceding phase before the commencement of a new phase.

In spiritual therapy, however, the therapist will be able to help the patient to experience his/her real self and, at the same time continue his/her clinical treatment, on the basis of the above-mentioned 6 principles (Willam, 2000).

The present study was designed to examine the effect of combination of spirituality and cognitive-behavioral family therapy on treatment of generalized anxiety disorders.

\section{Method}

\section{Participants}

This study examined two participants diagnosed with anxiety disorders. The diagnosis was made based on the clinical interview, DSM-IV-TR criteria, psychological tests and psychiatric diagnosis. The diagnosis was made based on the clinical interview, DSM-IV-TR criteria, psychological tests and psychiatric diagnosis.

\section{Participant 1}

Male, aged 43, with a Master degree in Economic, married, his wife was 40 years old, Master degree in Economic as well, they have two children a seven year boy and a four year girl).

Treatment Period: 55 sessions.

\section{Participant 2}

Female, aged 37, with a PhD degree, Physiotherapist, mar- ried, her husband was 39 years old, Businessman BA; they have a three year daughter.

Treatment Period: 39 sessions.

\section{Instruments}

In order to identify the disorders, the MMPI and SCL-90-R tests and the Beck Depression Inventory were administered to the participants, together with a clinical interview for both. The interviews were unstructured. Table 1 displays Scores on Beck Inventory, before, after and follow-up treatment.

Based on MMPI and SCL-90-R results (Diagrams 1 and 2), the first client was diagnosed with anxiety, depression, and physical complaints. The participants scored 29 on the long version and 12 on the short version of the Beck Depression Inventory. He was referred to a psychiatrist as well, who confirmed the existence of generalized anxiety and depression. Diagram 1 indicates the pre-treatment, post-treatment \& follow-up results of MMPI for the first client. Diagram 2 displays the pre-treatment, post-treatment and follow up results of SCL90-R Test for the first client.

As for the second client, the results of MMPI and SCL-90-R (Diagrams 3 and 4) showed dissatisfaction with physical conditions, anxiety and depression. The client scored 33 on the long version and 15 on the short version of the Beck Depression Inventory, which was indicative of severe depression. Moreover, the clinical interview and the psychiatric diagnosis confirmed the existence of generalized anxiety as the major disorder in her. Diagram 2 indicates the pre-treatment, post treatment \& follow-up results of MMPI for the second client. Diagram 4 displays the re-treatment, post-treatment and follow-up results of SCL-90-R Test for the second client.

\section{Therapeutically Procedures and Results}

Right at the beginning of the session, the client and their family members were informed of the results of the conducted tests. They were also notified that the sessions would both take place in a one to one basis or with the presence of the family members

In the initial session of the first client, he said that he was anxious since early childhood and he used to sleep next to her mother because of that. According to the client's report both his mother and his brother were on medication because of anxiety and depression. He described his marital relationship as restricted and poor. He thought that his wife was generally kind, but short-tempered and angry. The client also explained that he himself was a very irritable person. He emphasized the tensions in his muscles.

The second client complained of recurrent headaches. She said: "I have serious and lasting headaches and I feel anxious

Table 1.

Scores on Beck Inventory, before, after and follow-up treatment.

\begin{tabular}{ccc}
\hline & Long version & Short version \\
\hline Before treatment & 29 (first), 33 (second) & 12 (first), 15 (second) \\
After treatment & 7 (first), 9 (second) & 1 (first), 2 (second) \\
Follow-up & 6 (first), 10 (second) & 2 (first), 3 (second) \\
\hline
\end{tabular}




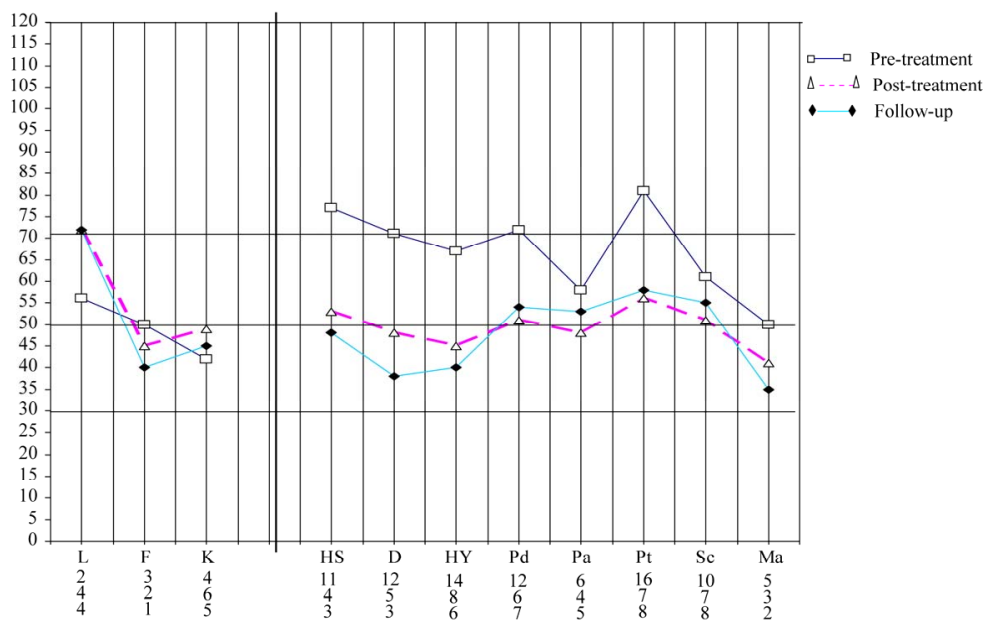

Diagram 1.

The pre-treatment, post-treatment \& follow-up results of MMPI (first client).

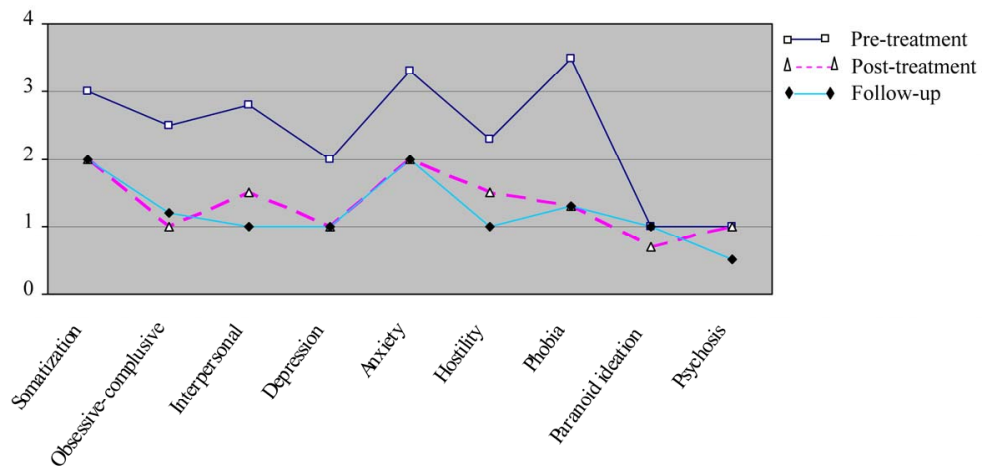

Diagram 2.

Pre-treatment, post-treatment and follow-up results of SCL-90-R test (first client).

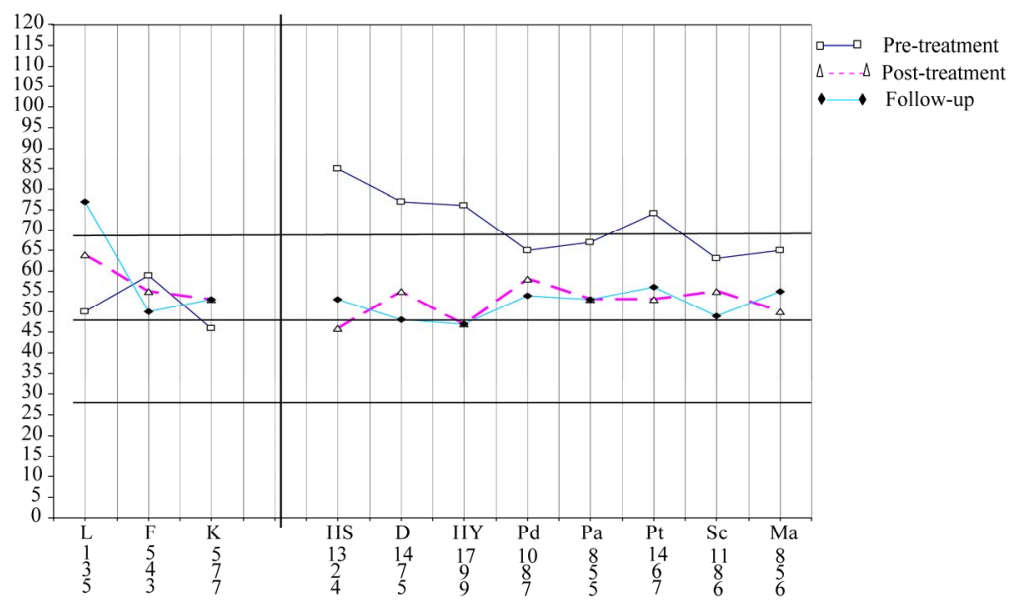

Diagram 3.

The pre-treatment, post-treatment \& follow up results of MMPI (second client).

and depressed at all times. My headaches increase in conditions of stress. Sometimes as a result of short breath and dizziness, I cannot do anything and cannot sleep either. I usually feel fatigued and I worry too much about my child's safety."

The therapist applied therapeutic techniques after evaluation and diagnosis of client's problems through clinical interview, testing and consulting with the psychiatrist. After the results confirmed the diagnosis of general anxiety disorders for both clients, the therapist applied cognitive-behavioral techniques such as self-monitoring, positive thinking, cognitive reconstruction 


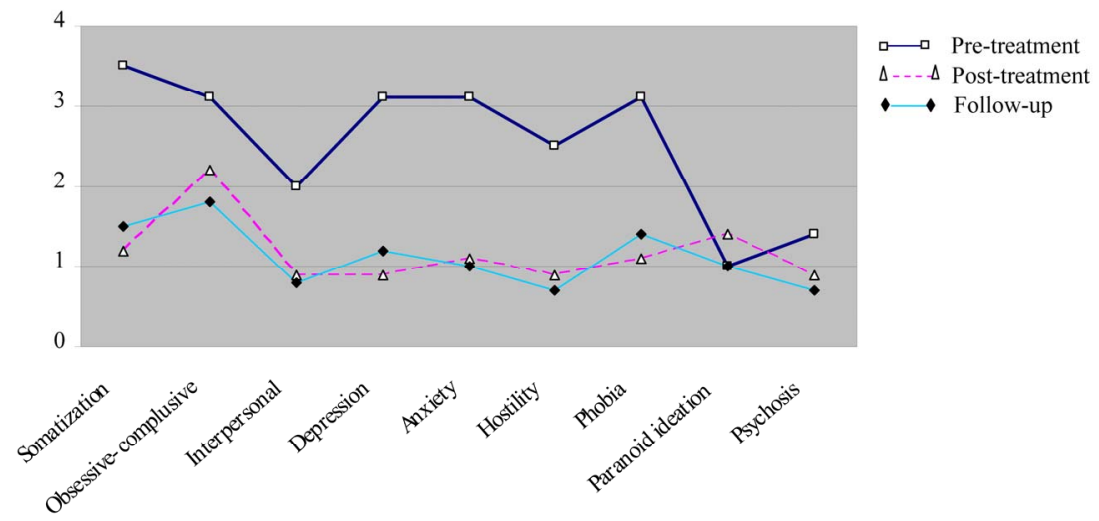

Diagram 4.

Pre-treatment, post-treatment and follow-up results of SCL-90-R test (second client).

imaginative desensitization and relaxation. The family members of the clients were also exposed to a series of programs including problem solving skills, communication skills with a focus on conflict resolution within the family Also, therapist taught to family members about anxiety and some skills such as problem solving and discussion about family conflicts. Furthermore, the therapist discussed and implemented integrative implications of spiritual therapy with an emphasis on shared love for all human beings, love for others regardless of their ethnicity, belief in monotheism and belief in the Day of Judgment and hereafter.

In the following sessions, the therapist concentrated on his method to help the clients to solve the problem through establishing a healthy, friendly and positive climate.

In regards to the client's improvement, the psychologist being the therapist here used the tests MMPI, SCL-90-R and the Beck Depression Inventory again and announced the results to the client. As Diagrams 1-4 showed the mental profiles of the clients are normal and without any symptoms of physical ailment, anxiety, depression, distress.

The sessions were associated with a good understanding of reflexive and proactive thinking and their different implications. The clients learned that the reflexive thoughts were mainly indicative of inner insecurity, negativity, doubt and counter productive suggestions whereas the proactive thoughts brought hopefulness, resourcefulness and positive thinking. The clients received coaching techniques to choose proactive thoughts instead of reflexive thoughts. Each session, the clients were given exercises to work on the enhancement of proactive thoughts for the following session. The exercises encouraged them to practice proactive thinking in between the sessions and examine the implications on their feeling $s$ and behaviors. In addition, the clients were exposed to a series of religious and spiritual interventions where the focus of conversations was on the relationship between meaning and God, values and spirituality, responsibility and spirit. The clients were asked to reflect on religious sayings such as God is closer to you than the vein of your neck. They were also invited to deeply think about the impact of God's compassion in their own life to the effect that the greatest sin would be the despair since despair would mean to turn your back on God. Clients were then encouraged to explore the implications of spirituality and religious instructions in their own phenomenological life namely their own lived experiences.

The psychologist subsequently asked for a gathering of all the members of the families. They got together and reviewed all the phases of therapeutically sessions. While they made sure of the health of the clients, they expressed their gratitude and thanked the therapist. The post-treatment MMPI and SCL-90-R results were normal for both clients. One year later, in the follow-up phase, none of the clients showed any signs of recurrence of the disorder.

\section{Discussion}

The present research was designed to investigate the efficiency of combination of spirituality and cognitive-behavioral family therapy on treatment of Generalized Anxiety Disorders. The family education program used conflict resolution, relaxation, individual and family positive thinking, and desensitization as its techniques. In addition, the therapist helped the promotion of family relationships and modification of the client's thinking pattern through family therapy and by encouraging cooperation among the family members. The techniques were all inspired by a focus on the integrative implications of spiritual therapy with an emphasis on shared love for all human beings, love for others regardless of their ethnicity, belief in monotheism and belief in the Day of Judgment and hereafter.

Child breeding techniques, socialization techniques of family members, family disciplinary conducts, class counterparts, society, school and the mass media are among the factors which affect the emergence and persistence of anxiety disorders (Cullinan, 2002). Treatments which are based on the cognitive-behavioral approach are highly efficient in curing anxiety disorders, particularly generalized anxiety disorder. Gradual desensitization, problem-solving methods, and cognitive reconstruction are among the techniques which helped the modification of anxiety and avoidance behaviors in the clients (see Barret, Dadds, \& Rappee 1996).

In this research, the pre- and post-treatment symptoms were assessed through clinical interview, psychological tests and the psychiatrist's opinion. In the family sessions, the role of family in the appearance and persistence of mental disorders, and in establishment of emotional relationships among the members, together with the nature of family conflicts was emphasised. Based on these, problem solving and positive thinking techniques were taught to the family members. Moreover, the disorder symptoms were controlled through application of selfregulation and relaxation, the techniques of which were taught 
too. Comparison of the pre- and post-treatment results of MMPI and SCL-90-R is indicative of improvement in the various indexes of the tests.

As demonstrated by the extra-analytical study by Shadish et al. (1993), numerous researches confirm the efficiency of family therapy in treatment of children and adult problems, since it identifies and modifies the behavior patterns which maintain the problem, the problematic attitude systems, and the structural, contextual and historical contributing factors. In the present study, this issue facilitated treatment and contributed to its continuation.

One of the probable reasons for the therapeutical effects of cognitive-behavioral techniques to have treated generalized anxiety disorder is due to the team work and the cooperation of a psychologist and family members with their emphasis on the client's religious, spiritual and ethical aspects by reinforcing these features in the clients. The results obtained from the present research are consistent with the results of the researches done by other researchers. Saavedra's (2002) case study concerning treatment of anxiety disorder in a client, confirmed the efficiency of the combined cognitive-behavioral and family therapy approach. Leggier et al. (2003) used individual cognitive-behavioral treatment for seven adolescents diagnosed with generalized anxiety. Also, he confirmed the efficiency of cognitive-behavioral family therapy.

Anxiety as a trait has a familial association. Although early studies produced inconsistent findings regarding familial patterns for Generalized Anxiety Disorder, more recent twin studies suggest a genetic contribution to the development of this disorder. Furthermore, genetic factors influencing risk of Generalized Anxiety Disorder may be closely related to those for Major Depressive Disorder (Culinan, 2007).

It can be concluded that if family members employ appropriate methods of resolving family conflicts, increase their emotional relationships, and, when necessary, correct their educational and breeding patterns, the conflicts and tensions of the person suffering from the disorder decrease as well. In addition, spirituality and cognitive techniques may help clients revise and rectify their thinking patterns. The present research has some limitations such as lack of control group and non-selective sampling group.

\section{REFERENCES}

Albucher, R. C. (2005). Phobic disorders. Ann Arbor, MI: University of Michigan.

American Psychiatric Association (2000). Diagnostic and statistical manual of mental disorders (4th ed.). Washington DC: American Psychiatric Association.

Barrett, P. M., Dadds, M. R., \& Rapee, R. M. (1996). Family treatment of childhood anxiety: A controlled trial. Journal of Consulting and Clinical Psychology, 64, 333-342. doi:10.1037/0022-006X.64.2.333

Culinan, D. (2007). Students with emotional and behavior disorders: An introduction for teachers and other helping professionals. New York: Pearson Education Inc.

Kanfer, F. H., Karoly, P., \& Newman, A. (1975). Reduction of childrens fear of dark by competence-related and situational threat-related verbal cues. Journal of Consulting and Clinical Psychology, 43, 257-258. doi:10.1037/h0076531

Legger, E., Ladoucer, R., Dugas, M. J., \& Freeston, M. H. (2003). Cognitive-behavioral treatment of generalized anxiety disorder among adolescents: A case series. Journal of the American Academy of Child \& Adolescent Psychiatry, 42, 327-330. doi:10.1097/00004583-200303000-00013

Saavedra, L. M. (2002). Case study: Disgust and a specific phobia of buttons. Journal of the American Academy of Child and Adolescent Psychiatry, 41, 1376-1379. doi:10.1097/00004583-200211000-00020

Shadish, W., Montgomery, L., Wilson, P., Wilson, M., Bright, I., \& Okwumabua, T. (1993). The effects of family and marital psychotherapies: A meta-analysis. Journal of Consulting and Clinical Psychology, 61, 992-1002. doi:10.1037/0022-006X.61.6.992

Yongsma, A. E., \& Dattilio, F. M. (2000). The family therapy: Treatment Planner. New York: John Wiley and Sons. 